\title{
CALCULATION OF SHEAR STRENGTH PROBABILITY OF GEOGRIDS USED IN HIGHWAY EMBANKMENTS
}

\author{
TUBA KUTUK-SERT ${ }^{1}$, ALI GURBUZ ${ }^{2}$ \\ ${ }^{1}$ Recep Tayyip Erdogan University, Department of Civil Engineering, Rize. \\ tuba.kutuk@erdogan.edu.tr \\ ${ }^{2}$ Recep Tayyip Erdogan University, Department of Civil Engineering, Rize. \\ ali.gurbuz@erdogan.edu.tr
}

\begin{abstract}
In this study; experimental measurement data were performed for probability analysis. Geogrids are crucial reinforced material for civil engineering applications such as highway base/subbase reinforcement, railway ballast reinforcement and retaining walls. In this study, the cumulative distribution function was formed to estimate the probability of collapse risk of the highways. Probability density functions were calculated with the help of lognormal mean and lognormal standard deviation values of highway displacement points. The cumulative distribution functions were generalized and the probability of the damage was shown. With the results of this work; damage possibility can be estimated for any highway reinforced with geogrid which has same features such as 30x30mm, 40x40mm and 50x50mm etc.
\end{abstract}

Keywords; highway reinforcement, damage estimation

1. INTRODUCTION In Turkey, slope and road embankment stability is very crucial problem. Especially Embankment settlement and deformations are difficulties frequently encountered on the highways. In recent years due to the increased amount of traffic, reinforcement of road layers has gain importance. Geogrids are crucial reinforced material for civil engineering applications such as highway base/subbase reinforcement, railway ballast reinforcement and retaining walls (Sert and Akpinar, 2010).
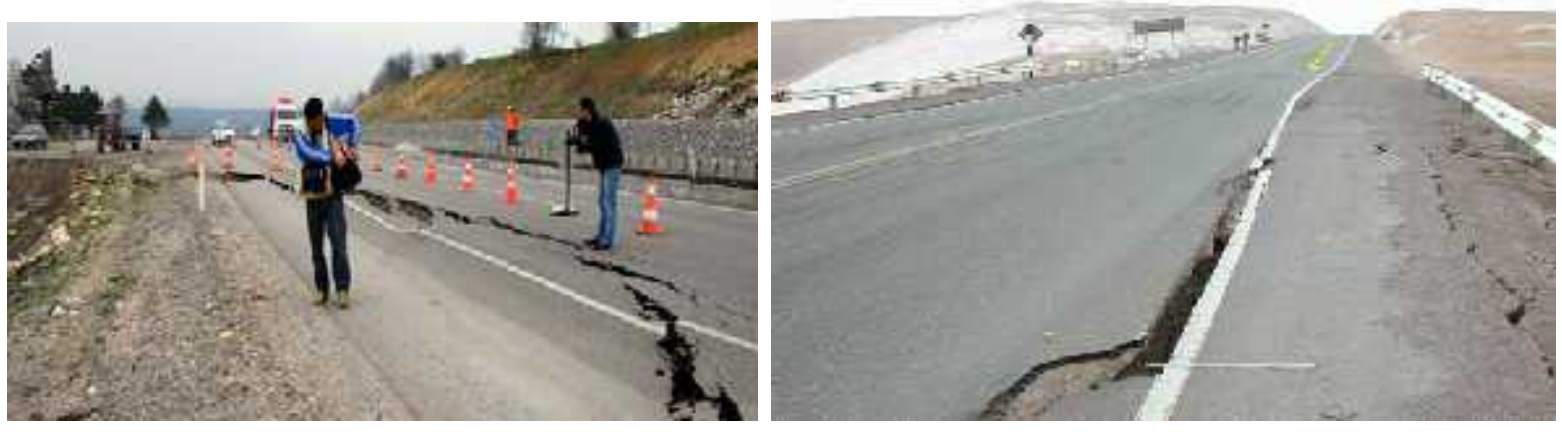

Figure 1. Highway settlements and shear deformations observed in Turkey (first one is from D-100 Highway stanbul-Ankara Direction, near Abant Intersection)

Thus, there has been an increasing importance on the study of highway deformations and risk assessments have become one of the necessary issue for loss estimate.

The loss estimation is based on the damage states of the structures and there are several models which can be used to quantify the damages, characterization of damage state and estimation of losses after the earthquakes (FEMA 1997, Hamid and Mohamad 2013). Fragility analysis is one of the key component in seismic risk assessment and more specifically in regional seismic risk assessment (Abo-El-Ezz, Nollet et al. 2013). 
In probability theory and statistics, the cumulative distribution function (CDF), describes the probability that a real-valued random variable " $X$ " with a given probability distribution will be found to have a value less than or equal to $\mathrm{x}$ (Zwillinger and Kokoska 2010). In the case of a continuous distribution, it gives the area under the probability density function from minus infinity to " $x$ ". Cumulative distribution functions are also used to specify the distribution of multivariate random variables (Gentle 2009).

2. GEOGRID REINFORCEMENT Geogrids are usually evaluated in civil engineering applications such as roads, dams, landfills and others. Geogrids are geosynthetic products with apertures that are characterized by a coexist of transverse and longitudinal ribs. These transverse and longitudinal ribs enable interface shear contributions, passive, force and geogrid pullout resistance.
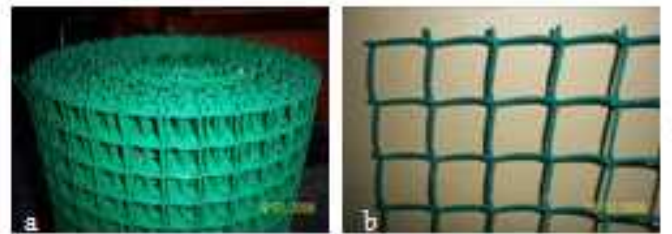

$30 \mathrm{~m} \times 30 \mathrm{~mm}$ square aparture size
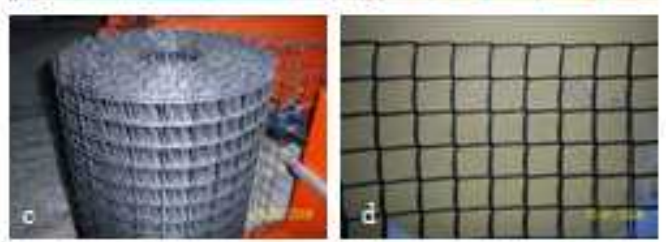

$40 \mathrm{~m} \times 40 \mathrm{~mm}$ square aperture size
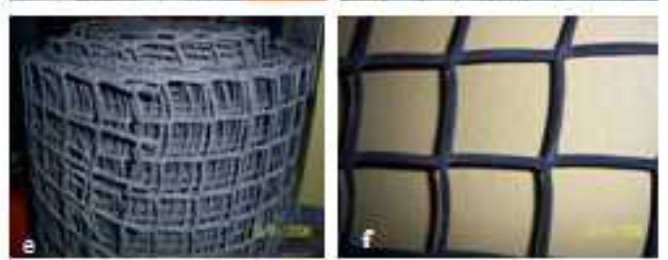

$50 \mathrm{~m} \times 50 \mathrm{~mm}$ square aperture size
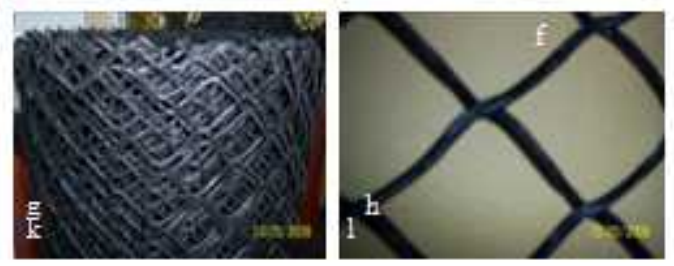

Crosswise aperture size

Figure 2. Geogrid types used in this study.

Four types of geogrids which are $50 \mathrm{~mm}$ x $50 \mathrm{~mm}, 40 \mathrm{~mm}$ x $40 \mathrm{~mm}, 30 \mathrm{~mm}$ x $30 \mathrm{~mm}$ square aperture size geogrids and crosswise aperture size geogrids as can be indicated in Figure 2 were investigated. Table 1 shows the dimension properties of these geosynthetic materials.

Table 1. Dimensions of geogrids

\begin{tabular}{|c|c|c|c|}
\hline Geogrid Aperture Type & $\begin{array}{c}\text { Aperture width (b) } \\
\text { mm }\end{array}$ & $\begin{array}{c}\text { Aperture length (h) } \\
\text { mm }\end{array}$ & $\begin{array}{c}\text { Rib width (w) } \\
\text { mm }\end{array}$ \\
\hline $50 \mathrm{~mm}$ x 50 mm, Square & 50 & 50 & 17 \\
\hline $40 \mathrm{~mm}$ x 40 mm, Square & 40 & 40 & 15 \\
\hline $30 \mathrm{~mm}$ x 30 mm, Square & 30 & 30 & 13 \\
\hline Crosswise & 70 & 82 & 23 \\
\hline
\end{tabular}

3. The Test Procedure And Device The pullout test mechanisms were used for determining geogrids' shear and tensile performance that are in compacted soil. The pullout interaction mechanisms between geogrid and soil are exclusively complex. Two cases come out of geogrid's pullout test procedure. The first one, interface shear resistance that takes place along the longitudinal ribs and the transverse ribs. The second one, the passive resistance that develops against the front of transverse ribs. 
The pullout test apparatus is the first in Turkey with its dimensions. Figure 3 shows picture of pullout test apparatus that is built at Karadeniz Technical University. The dimensions of the box are $1 \mathrm{~m}$ length $\mathrm{x} 1 \mathrm{~m}$ width $\mathrm{x} 0.80 \mathrm{~m}$ height. The pullout test device is constituted of a rigid pullout box that have steel profiles, a vertical and horizontal pistons, a clamping system, and measurement sensors (pressure gages, strain gages, vertical and horizantal LVDTs ) and data acquisation system.

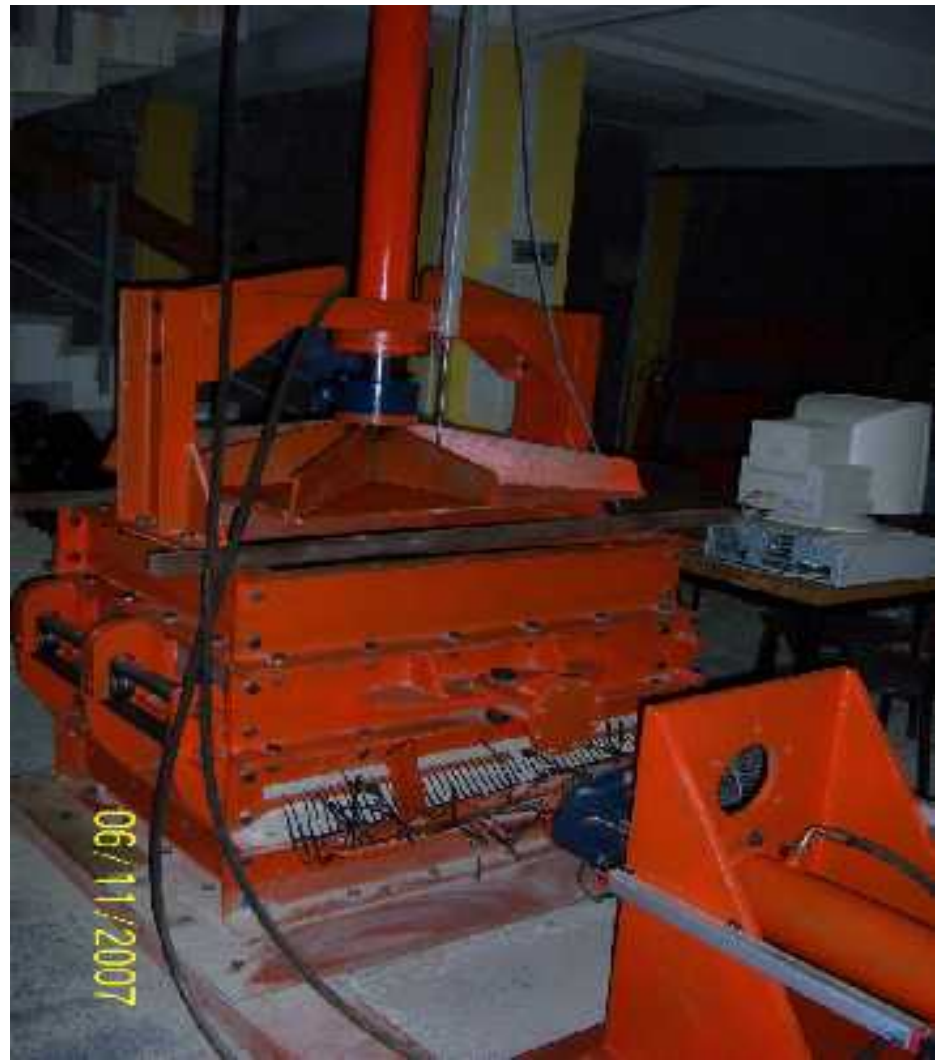

Figure 3.1 The Pullout Test Device

In the pullout test, aggregate is spread to the geogrid level in the pullout box. The geogrid is placed in half of the pullout box. Up to the half of the box subgrade material is put; above the geogrid level, subbase material is spread. Placed aggregate material are considerably compacted. After compression is made at every level, the pullout force is applied to geogrid under vertical pressure. $35 \mathrm{kPa}$ vertical pressure is applied in each test. The pullout force is applied to geogrid under constant test speed which is equal to $5 \mathrm{~mm} / \mathrm{min}$.

4. Description Of The Proposed Methodology: It is possible to use linear or nonlinear methods in seismic analyses of structures. Linear analysis uses the methods of the elastic solution. Inelastic behavior includes to solution by specific coefficients. Results obtained from elastic analyses are lower realistic than inelastic analyses (Tekin, Gürbüz et al. 2013). It is need to include inelastic behavior of structural elements for more realistic results. Nonlinear time history (TH) analysis is the represents the most actual behavior of the structure. However, developing computer technologies provide easy to carry out it. TH analyses need to long time period bacause of multi-parameter solution way. Seismic loads are applied to the building directly in TH method. Earthquake data should be selected carefully. Past studies shows that nonlinear pushover (NSP) analysis is suitable alternative to TH by correct selection of parameters and assumptions (Saidi and Sozen 1981).

Fragility curve is a useful tool for predicting damage risk of structures with similar characteristics such as material, height and design code level(Abo-El-Ezz, Nollet et al. 2013). The curves can be formed empirical, heuristic or analytical based methods(Singhal and Kiremidjian 1996, Porter, Kiremidjian et al. 2001, Rossetto and Elnashai 2003, Wu, Tesfamariam et al. 2012, Zhang and Hu 2005 ). The principle of the analytical method which is preferred in this study is to analyze the damage state of highways.

In addition, fragility curves are cumulative distribution functions that probability of reaching or exceeding a damage state as demand parameters such as story drift ratio(SDR), peak ground acceleration (PGA), spectral acceleration (Sa) or spectral displacement (Sd) (Serdar Kirçil and Polat 2006, Lignos and Karamanci 2013, Su and Lee 2013), (Hsieh, Lee et al. 2013, Suppasri, Charvet et al. 2013). It has been widely accepted that spectral 
displacement can be closely correlated with seismic damage of structures(Serdar Kirçil and Polat 2006) (Su and Lee 2013).

Probability density function of a random variable with lognormal distribution is as follows equation-1:

$f(x)=\frac{1}{\Delta U_{Y} \sqrt{{ }_{L}}} \exp -\left[-\frac{\left(h-\mu_{Y}\right)^{2}}{2 U_{Y}{ }^{2}}\right],(0<x<+\infty)($ Eq. 1$)$

In this distribution; $\mu_{Y}$ is lognormal mean of variable $\mathrm{Y}$ and $\sigma_{Y}$ is lognormal standard deviation of variable Y. $\mu_{X}$ ve $\sigma_{X}$ are associated with $\mu_{Y}$ ve $\sigma_{Y}$ by equation-2 and equation-3.

$\mu_{Y}=b\left[\mu_{X} / \sqrt{\left(\frac{u_{X}^{2}}{\mu_{X} x^{2}}+1\right)}\right]($ Eq.2)

$\sigma_{Y}=\sqrt{l\left(\frac{u_{X} x^{2}}{\mu_{X} x^{2}}+1\right)}($ Eq.3)

Probability of having a specific range of a continuous random variable can be written as equation-4:

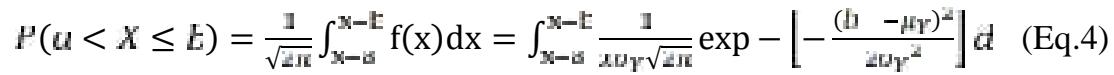

Probability distribution of earthquake damage is assumed to be lognormal distribution. Thus, the analytical expression of fragility curve for a damage level is written as the follows equation-5

$P \geq\left(d_{S_{l}} \mid S_{a}\right)=\varphi\left(\frac{\ln \left(S_{\square}\right)-\overline{S_{a_{a_{l}}}}}{\beta_{a_{\Omega_{l}}}}\right)($ Eq.5)

$P_{d}$ is probability of damage. $S_{d}$ is modal displacement. $d_{S_{\tilde{l}}}$ is modal displacement for damage level "i". $\overline{S_{a_{\Sigma_{i}}}}$ is mean modal displacement for damage level "i". $\beta_{a_{a_{l}}}$ is lognormal standard deviation of modal displacement values for damage level " $\mathrm{i}$ ”. $\varphi$ is cumulative distribution function.

Fragility curves can be formed empirical, analytical or heuristic based methods (Singhal and Kiremidjian 1996, Porter, Kiremidjian et al. 2001, Rossetto and Elnashai 2003, Wu, Tesfamariam et al. 2012, Zhang and Hu 2005 ). In this study, analytical fragility curves were obtained by experimental shear strain analysis.

Besides analytical fragility curves were obtained by shear strenght values of highways with variable square aperture size geogrid.

5. Analytical Results: The principle of the analytical method is based on the pullout test analyze. In the pullout test, aggregate is spread to the geogrid level in the pullout box. The geogrid is placed in half of the pullout box. Up to the half of the box subgrade material is put; above the geogrid level, subbase material is spread. Placed aggregate material are considerably compacted. After compression is made at every level, the pullout force is applied to geogrid under vertical pressure. $35 \mathrm{kPa}$ vertical pressure is applied in each test.

Each procedure was applied for all geogrid types. Totally, 4 shear strength versus displacement graphics were obtained. Figure 5.1 shows that shear strength versus displacement graphics of 4 geogrid types. 


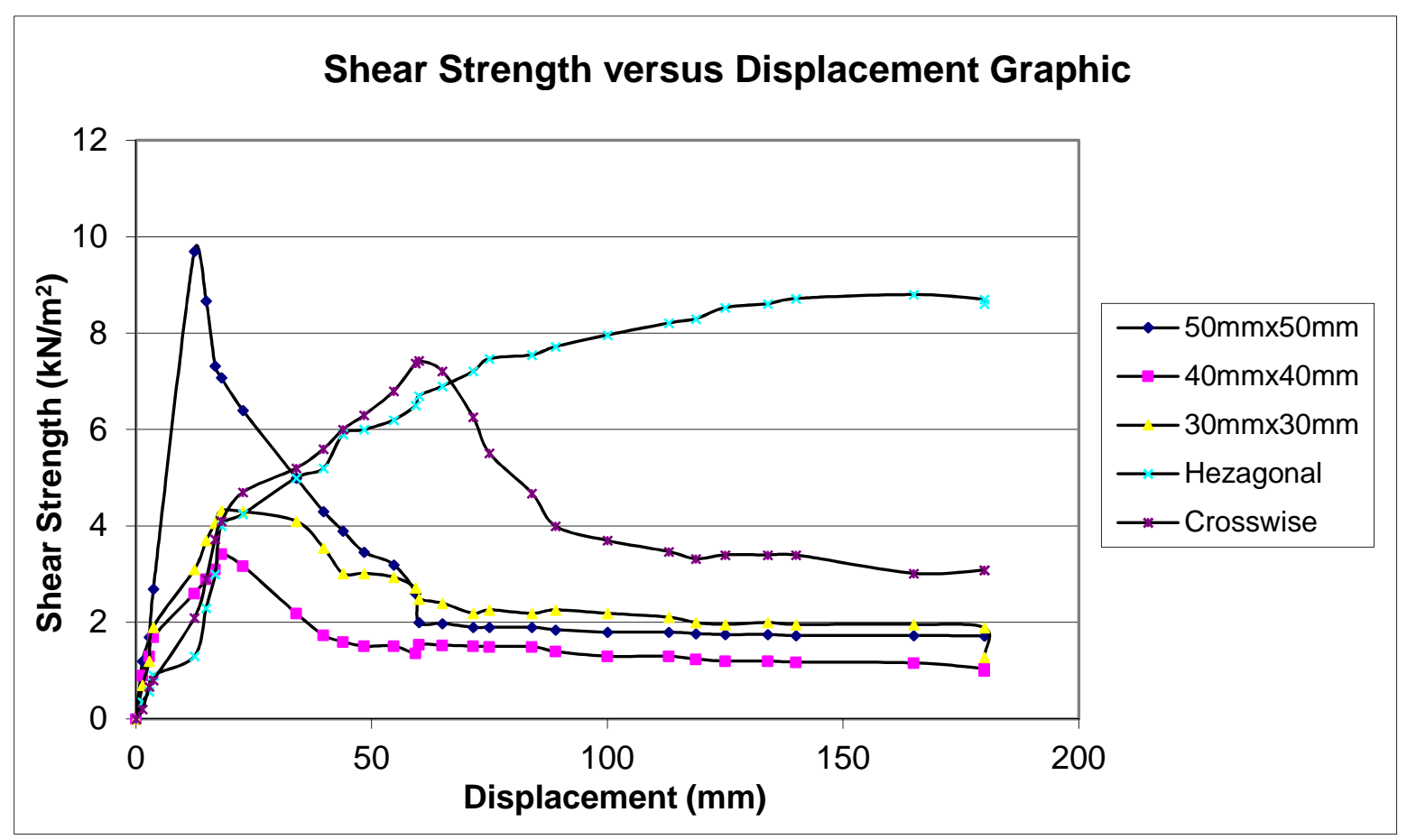

Figure 5.1. Shear strength versus displacement graphics of variable square aperture size geogrid

After the obtaining capacity curves of materials; critical shear strenght values were calculated for related geogrids. Table 5.1 shows the obtained test data inventory for fragility analyze.

Table 5.1. Obtained test data inventory

\begin{tabular}{|l|l|l|}
\hline \multicolumn{1}{|c|}{ Model Code } & $\begin{array}{c}\text { Aperture } \\
\text { size } \\
\text { (mm) }\end{array}$ & \multicolumn{1}{|c|}{$\begin{array}{c}\text { Shear } \\
\text { Strength } \\
\text { (kN/m } \mathbf{m}^{2}\end{array}$} \\
\hline B_01 & $30 \times 30$ & 4,06 \\
\hline B_02 & $30 \times 30$ & 4,32 \\
\hline B_03 & $30 \times 30$ & 4,3 \\
\hline B_04 & $30 \times 30$ & 4,1 \\
\hline B_05 & $30 \times 30$ & 3,55 \\
\hline B_06 & $40 \times 40$ & 3,42 \\
\hline B_07 & $40 \times 40$ & 3,17 \\
\hline B_08 & $40 \times 40$ & 3,1 \\
\hline B_09 & $40 \times 40$ & 2,9 \\
\hline B_10 & $40 \times 40$ & 2,6 \\
\hline B_11 & $50 \times 50$ & 9,7 \\
\hline B_12 & $50 \times 50$ & 8,67 \\
\hline B_13 & $50 \times 50$ & 7,32 \\
\hline B_14 & $50 \times 50$ & 7,08 \\
\hline B_15 & Crosswise & 8,61 \\
\hline B_16 & & 6,4 \\
\hline
\end{tabular}




\begin{tabular}{|l|l|l|}
\hline B_17 & Crosswise & 8,72 \\
\hline B_18 & Crosswise & 8,8 \\
\hline B_19 & Crosswise & 8,7 \\
\hline B_20 & Crosswise & 8,61 \\
\hline
\end{tabular}

Mean shear strenght value and lognormal standard deviation of values for each material type was utilized for fragility analyze. Fragility curves are assumed cumulative distribution functions that probability of reaching or exceeding a damage state as demand parameters of shear strenght.

Thus, probability density functions were calculated for four material types. Figure 5.2 shows probability density function graphics for four materials.

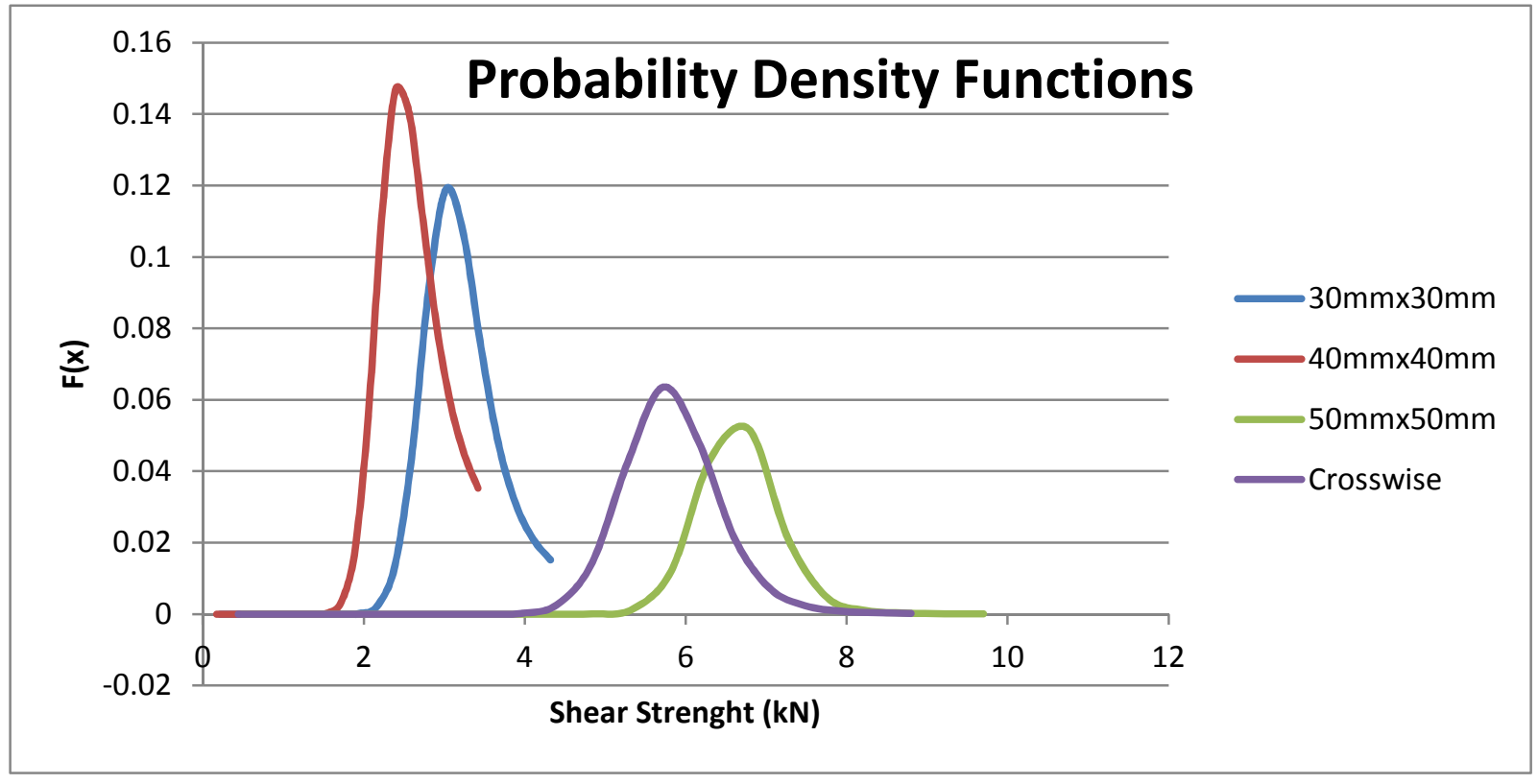

Figure 5.2. Probability density function graphics

The area under the line shows that probability of damage in probability density functions. Figure 5.3 shows the transformation of probability density function to cumulative distribution function.

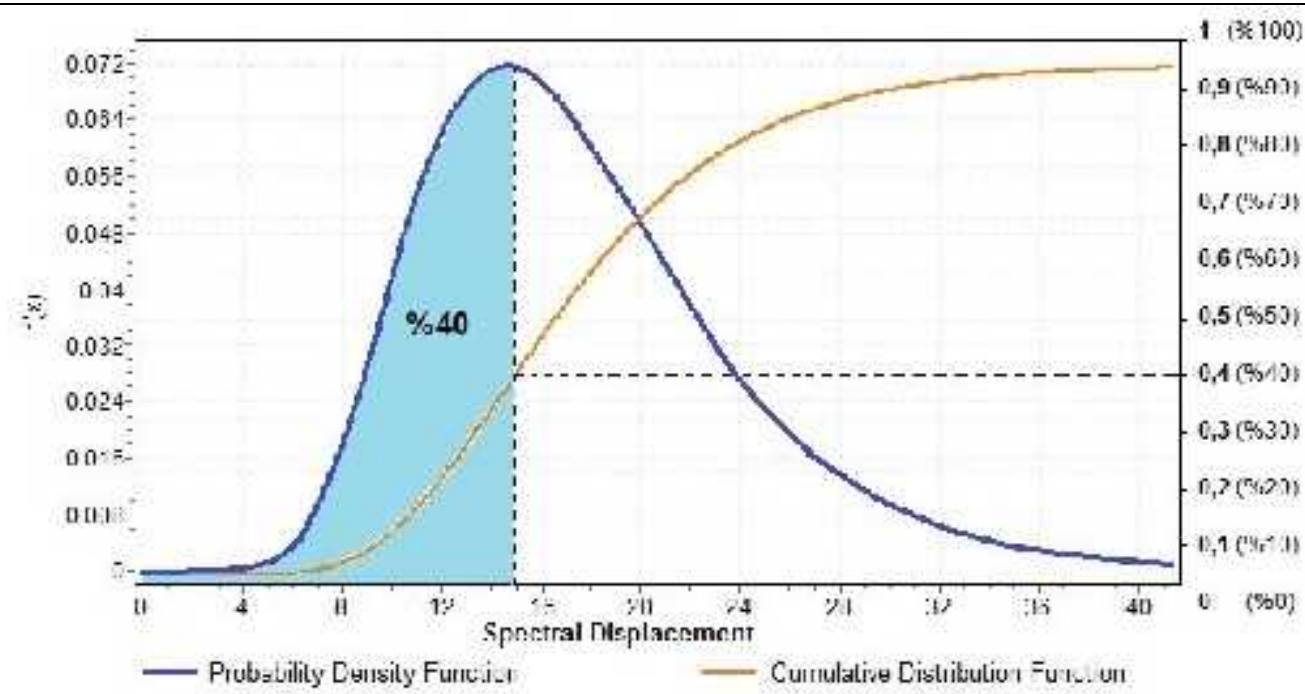

Figure 5.3; Transformation of probability density function to cumulative distribution function. 
Fragility curves of slight, moderate, external and complete damage level for all buildings are shown in Figure 4.5.

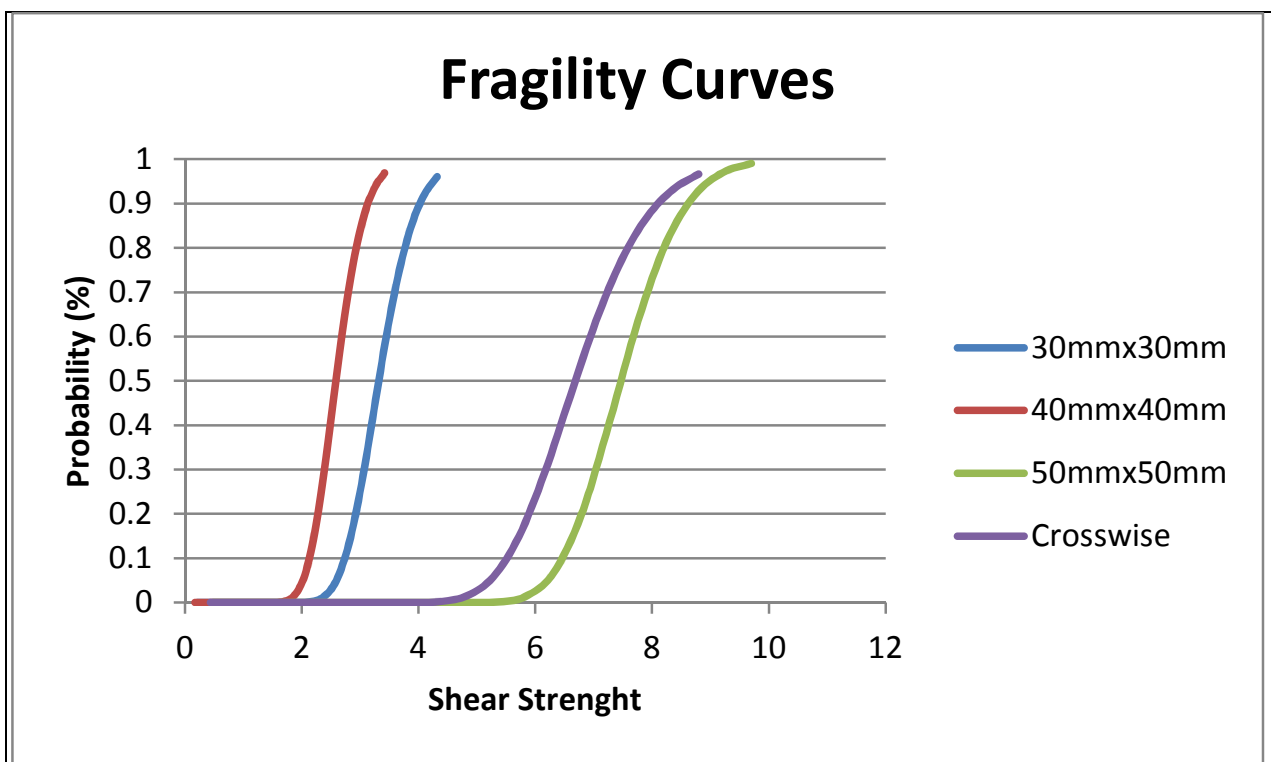

Figure 5.4. Fragility curves

Conclusions :In this study, cumulative distribution functions were formed for 4 different type geogrid materials. Probability density functions were calculated with the help of lognormal mean and lognormal standard deviation values of limit states. Then, fragility curves that show probability of the damages according to shear strength limits.

According to experimental results; 40x40mm square aperture size geogrid has lower shear strenght capacity compared to other types. However capacity curves give information about the current status of the materials, there are lots of different measuring point and material types located in highways. Therefore, probability studies and rapid risk assessment methods are required. Therewith, a general assessment can be made by the results of the fragility curves.

By the result of this study, cumulative distribution functions were applied as an shear strenght estimation graphics. The rupture on the geogrid samples were observed just outside the pullout test box. Some reasons that is occurred this situation may be vertical pressure effect, max. soil compaction, pullout rate, soil gradation type and geogrid's horizontal- longitudinal rib effect.

Among geogrids with square aperture dimensions, as aperture dimensions get larger, aggregate penetrate capacity become higher and this type of geogrid $(50 \times 50 \mathrm{~mm}$ square aperture size geogrid) has higher strength value. So, this geogrid type can be used as a prime reinforcement for subbase structures.

\section{REFERENCES}

[1] Zwillinger, Daniel; Kokoska, Stephen (2010). CRC Standard Probability and Statistics Tables and Formulae. CRC Press. p. 49. ISBN 978-1-58488-059-2.

[2] Gentle, J.E. (2009). Computational Statistics. Springer. ISBN 978-0-387-98145-1. Retrieved 2010-0806.[page needed]

[3] Abo-El-Ezz, A., M.-J. Nollet and M. Nastev (2013). "Seismic fragility assessment of low-rise stone masonry buildings." Earthquake Engineering and Engineering Vibration 12(1): 87-97.

[4] Hsieh, M.-H., B.-J. Lee, T.-C. Lei and J.-Y. Lin (2013). "Development of medium- and low-rise reinforced concrete building fragility curves based on Chi-Chi Earthquake data." Natural Hazards 69(1): 695-728.

[5] Lignos, D. G. and E. Karamanci (2013). "Drift-based and dual-parameter fragility curves for concentrically braced frames in seismic regions." Journal of Constructional Steel Research 90: 209-220.

[6] Porter, K. A., A. S. Kiremidjian and J. S. LeGrue (2001). "<TR139_Porter.pdf>." Earthquake Spectra 17(2): 291-312. 
[7] Rossetto, T. and A. Elnashai (2003). "Derivation of vulnerability functions for European-type RC structures based on observational data." Engineering Structures 25(10): 1241-1263.

[8] Serdar Kirçil, M. and Z. Polat (2006). "Fragility analysis of mid-rise R/C frame buildings." Engineering Structures 28(9): 1335-1345.

[9] Singhal, A. and A. S. Kiremidjian (1996). "Method for Probabilistic Evaluation of Seismic Structural Damage." Journal of Structural Engineering 122(12): 1459-1467.

[10] Su, R. K. L. and C.-L. Lee (2013). "Development of seismic fragility curves for low-rise masonry infilled reinforced concrete buildings by a coefficient-based method." Earthquake Engineering and Engineering Vibration 12(2): 319-332.

[11] Suppasri, A., I. Charvet, K. Imai and F. Imamura (2013). "Fragility curves based on data from the 2011 Great East Japan tsunami in Ishinomaki city with discussion of parameters influencing building damage." Earthquake Spectra: 131218125838008.

[12] Tekin, M., A. Gürbüz and A. Demir (2013). "COMPARISON OF NONLINEAR STATIC AND DYNAMIC ANALYSES ON A R/C BUILDING " Mathematical and Computational Applications 18 (3): 264-272.

[13] Sert, T., Akpinar, M. V., “An Investigation on Pullout Test Device Dimensions” 9th

[14] International Congress on Advances in Civil Engineering ACE 2010, Karadeniz Technical

[15] University, Trabzon, Turkey, 27-30 September 2010, pp. 344.

[16] Wu, D., S. Tesfamariam, S. F. Stiemer and D. Qin (2012). "Seismic fragility assessment of RC frame structure designed according to modern Chinese code for seismic design of buildings." Earthquake Engineering and Engineering Vibration 11(3): 331-342.

[17] Zhang, J. and S. Hu ( 2005 ). "State of the Art of Bridge Vulnerability Analysis Research." Structural Engineers 21(5): 76-80.

[18] M. Saiidi and M. A. Sozen, Simple nonlinear seismic analysis of R/C structures. Journal of the Structural Division, ASCE 107, 937-51, 1981. 